\title{
A Study on Work from Home: Opportunities and Challenges in the Electricity Sector in Omanduring COVID-19 -A Case Study.
}

\author{
Saif Said Hamed Al Badi ${ }^{1}$, Dr. Syed Aulia Mohiuddin ${ }^{2 *}$ \\ ${ }^{1}$ MBA-Alumnus - Department of Management Studies Middle East College Oman. \\ ${ }^{2}$ Senior Faculty - Department of Management Studies Middle East College Oman.
}

*Corresponding Author: Dr. Syed Aulia Mohiuddin, Senior Faculty - Department of Management Studies Middle East College Oman

\begin{abstract}
In March 2020, the World Health Organization declared the coronavirus disease 2019, also called COVID-19, a pandemic. There is a considerable consequence of this pandemic, a lot of countries close their boundaries to protect themselves. Also, many companies are affected by the pandemic, within a short span of time Coronavirus has blown across the world, affecting the global economy and decreasing the markets, resulting in extreme losses for all. At the same time, many governments take precautionary measures to combating the pandemic.

Oman, also affected by the COVID-19 pandemic. It was starting from the beginning of the first quarter of 2020, the pandemic spreading over Oman. On April 10 2020, the Oman government procedure imposed precautionary measures to control the pandemic's spreading, including putting all government sectors under lockdown. Electricity sector affected by the precautionary measures, $70 \%$ of the staff was working from home, a lot of them were facing many challenges to achieve the work assigned from them, and a lot of technical issues happened at the same time pandemic. An attempt has been made to study the different factors, opportunities and challenges faced by the electricity sector in Oman -A case study of Nama holding company.
\end{abstract}

Key words: COVID-19, Pandemic, Work from Home, Remotely, Remote worker, Nama.

\section{INTRODUCTION}

Oman Electricity Sector is one of the success stories in the GCC. The Electricity sector was under the Ministry of Housing, water, \& Electricity ministry from 1970 till mid-2005. Starting from 2005, privatization started in all the electricity sector, but still owned by the government.

A study conducted by The King Abdullah Petroleum Studies and Research Center (KAPSARC) under the title of (Oman Electricity Sector: Features, Challenges, and Opportunities for Market Integration); said that the expected change in the electricity sector aimed to digging the reform initiatives and enhancing the electricity market by market liberalization.

That changed in the electricity sector structure has led to many changes at several levels like increasing the supplied energy and expansion in electricity service delivery into many small cities and rural villages around the sultanate. Also, the service level and quality are changed to meet the people's expectations and needs. These changes were not limited to public and government services but was also a leading supplier for industry, tourism, and other trade activities.

In Oman, on Feb 24 2020, the first case was confirmed when two citizens tested positive for the coronavirus (COVID-19) test after returning from Iran's Islamic Republic. On Apr 10 2020, all the government sectors were put under lockdown until Apr 22 2020. Then the decision of locked down was extended till May 29 2020. (Ministry of Health, 2020).

After spreading of the Coronavirus globally, it appears to all companies -especially Electricity companies- that it should consider the Work from Home (WFH) approach as an essential part of the business continuity plan and consider it a solution to many other challenges. It has been well demonstrated the importance of working from Home within the same crisis period.

The Work from Home decision was a hasty decision in many organizations, especially those with infrastructure that is not suitable and not equipped to handle remotely working approaches. 
Simultaneously, the approach leads to other issues and many additional security challenges, which will also be an extra burden for the IT staff. Furthermore, instead of solving the main problem, it is making a bad situation even worse. Moreover, in addition to what was mentioned, the organizations will inject much investment to prepare the IT infrastructure, enhance the security, and provide a technology that helps them adapt the Work from Home approach. All these efforts and investments will take time, which will be affecting productivity and increasing expenditure.

In the meantime, it is undeniable that the Work from Home approach is an elegant solution for many other issues like the need for more office space, more parking space, pollution, congestion, and many, but a careful study should precede it.Interestingly, the main driver for the digital transformation in Oman as well as other countries is the COVID-19. Whether it is government or private sector, various institutions were encountered resistance to change, regardless of whether the resistance was from the management itself or staff.

Work from Home has a lot of advantages; it is not limited only to the financial and life balance, but also the climate is getting the benefits of lockdown. It is a big chance to try a new strategy that depended on a win-win strategy. Both the staff and the company get the benefit of Work from Home approach.

\subsection{Aims and Objectives of the Study}

This research aims to study the Work from Home approach and study the opportunities and challenges with full consideration of Oman's telecommunication backbone's nature. Furthermore, understanding the nature of the Electricity sector needs and requirements and how it can benefit from this approach.

The objective can be summarized in the following:

1- To investigate the technological challenges to Work from Home in both main Cities \& rural areas of Oman. The investigation will help to deeply understand the challenges and make a proper decision based on the investigation results.

2- To examine the impact of Work from Home on staff productivity and work performance.

3- To assess the electricity sector's effectiveness in providing a stable service that supports the Work from Home initiatives.

\subsection{Study Questions}

A. How Work from Home approach can adopting in the electricity sector, and what the opportunities and challenges?

B. Is the Electricity sector ready for the Work from Home approach? (remote working capability, endpoint monitoring, the readiness to access all critical applications over on Web/VPN, etc.)

C. What the expected significant cybersecurity risks of Working From Home? Moreover, how will the sector deal with it?

\subsection{Scope of the Research}

The coverage of this study is the impact of the COVID-19 on the electricity sector in Oman. It covers the challenges and opportunities in the electricity sector during the COVID-19. The study does not cover all NAMA groups, but it is limited to some of the subsidiaries without mentioning them. This study focuses on the technology changes during the COVID-19 pandemic, perks, opportunities, and the pandemic's consequences. The study does not cover any things out of the Work from Home approach and its consequences.

\section{LITERATURE REVIEW}

With a growing number of affected people, companies, organizations, and countries with COVID-19 and its consequences is evidence of the most considerable economic shock the world has experienced in decades. Within the COVID-19 crisis period, all companies and government ministries must prepare their business continuity plan to ensure continuity of the Work. Otherwise, the effect of the crisis will be worse than expected. 
As per the June 2020 Global Economic Prospects, there is a "baseline forecast envisions a 5.2 percent contraction in global GDP in 2020, using market exchange rate weights - the deepest global recession in decades". As a result of that, there are expectations to "lower investment, an erosion of human capital through lost work and schooling, and fragmentation of global trade and supply linkages." (The World Bank Group, 2020)

When talking about the electricity sector and its importance to all parties, whether it is the government sector, health sector, industrial sector, or individuals, any prolonged outage will lead to a disastrous impact that can last a long time.

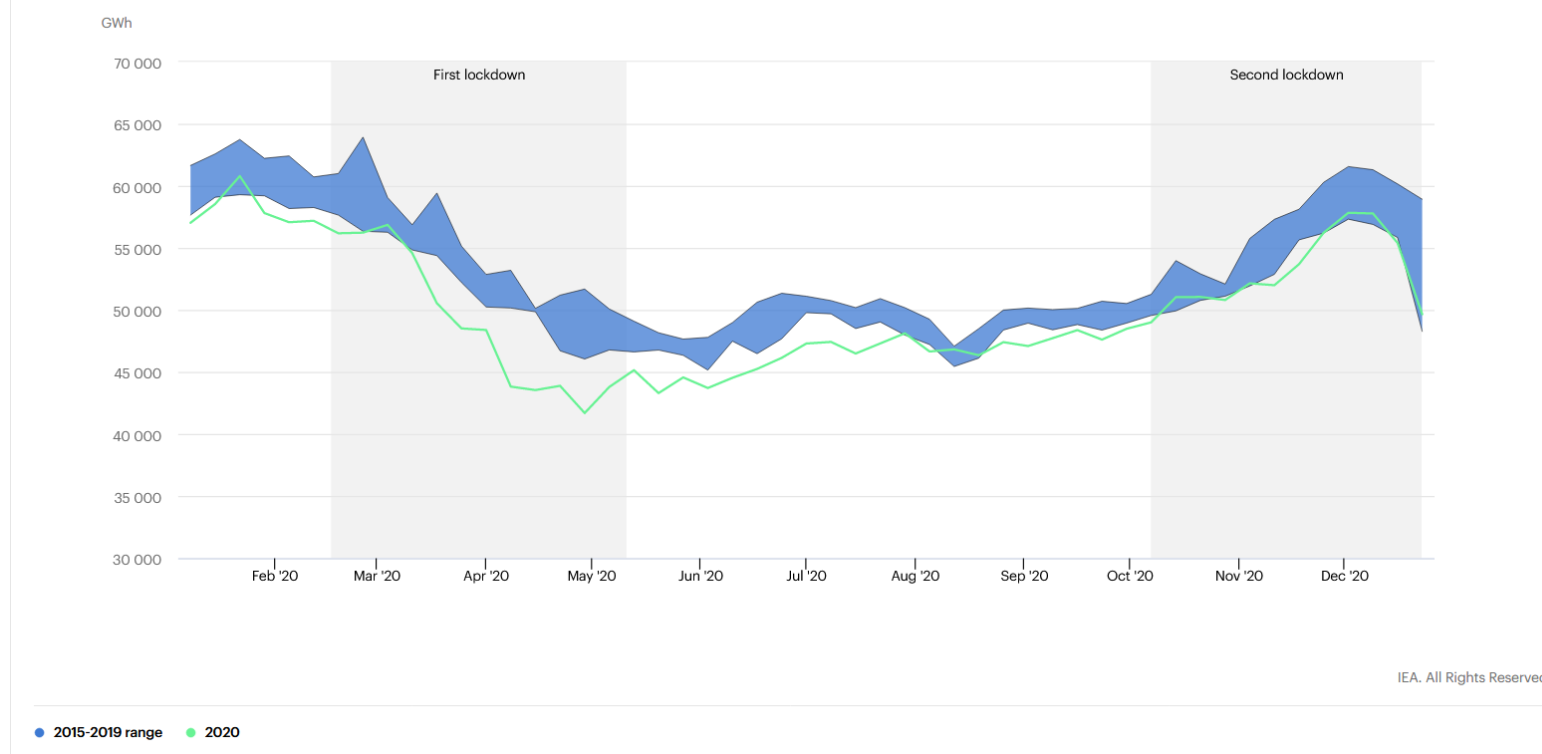

Figure4. Weekly electricity net generation in the European Union, 2015-2019 range compared with 2020. Source (IEA.org, 2020)

As the International Energy Agency noted in a "Covid-19 impact on electricity" report, electricity demand reduced within the COVID-19 lockdown. However, this does not conflict with the significant role of Electricity in the economy. The electricity drop in demand comes down to the lockdown measures taken by the governments. After lockdown measures were eased, the electricity demand preliminary returned to normal levels. This underscores the importance of the electricity sector and its role in the country's overall development.

\subsection{Impact of COVID-19 Worldwide}

In March 2020, there are a lot of changes that happened all over the world because of COVID-19. The COVID-19 pandemic had an almost immediate effect on all semblance of normal life in the world from East to West without any exceptions.

There are many consequences of the pandemic that impacted all economic activities and human life on the globe. The impact includes and is not limited to countries' border closures, quarantine, closing a lot of economic activities like hotels, restaurants, malls, gyms, and many other activities that there is no room to mention. It is worth that transportation challenges affect many industries and logistics, which, in turn, affect the remaining sectors.

Some sectors were ready to adapt to the situation and the COVID-19 consequences, but in exchange, there are a lot of sectors, organizations, and people who were not ready and not able to adapt to the consequences. Arguably, this goes back to many reasons, like telecommunication infrastructure's ability to meet and respond to both organizations' and individuals' demands and needs. Furthermore, a lot of small and medium enterprises have not sufficient resources to implement solutions to facilitate the implementation of remote working technologies. (Steven Fraser And Dennis Mancl. 2020).

And besides, most stock markets globally were affected by COVID-19 and fell sharply. (Gunther, Desroziers. 2020) 
A Study on Work from Home: Opportunities and Challenges in the Electricity Sector in Omanduring COVID-19 -A Case Study.

An Oxford Business Group study showed that "the energy sector was dramatically affected by the outbreak of the pandemic." (Oxford business group. 2020).

There is a substantial negative impact of the COVID-19 globally. The below table shows the top negative economic impact as per the Visual Capitalist official website:

\begin{tabular}{|l|l|l|}
\hline Rank & Factor & $\%$ Change (2020 vs. 3-Yr Avg) \\
\hline 1 & Competition in-network services & $-2.90 \%$ \\
\hline 2 & Collaboration between companies & $-2.60 \%$ \\
\hline 3 & Competition in professional services & $-2.30 \%$ \\
\hline 4 & Competition in retail services & $-1.80 \%$ \\
\hline 5 & Ease of finding skilled employees & $-1.50 \%$ \\
\hline
\end{tabular}

Table1. Top Negative Impacts of COVID-19. Source:(visual capitalist, 2020)

Needless to say that all sectors affected by COVID-19 without any exceptions, whether the impact is positive or negative.

\subsection{Impact of COVID-19 in Oman}

Oman, like other countries, is affected by the COVID-19 pandemic. It was starting from Feb 24 2020, the pandemic spreading over Oman. On April 10 2020, the Oman government procedure imposed precautionary measures to control the pandemic's spreading, including putting all government sectors under lockdown. The lockdown was not limited to the government only but also extended to include all sectors like education, tourism, industrial, and many others. Furthermore, it came down to close all country's land, sea, and air borders. (Ministry of Health. 2020). As per the World Bank, Oman's economy "is projected to sharply contract by over $9 \%$ in 2020, owing to depressed global demand for oil and the pandemic hit to the non-oil sector." (The World Bank Group. 2020)

\subsection{COVID-19 Challenges}

As per the Sultan Qaboos University in Oman, the impact of the COVID-19 has a huge impact on all aspects of the development globally and locally. When it has come to Oman's effect, Industry has slowed down due to movement restriction between countries. Also, travel and tourism have been disrupted, which in turn in other businesses like transportation and Hotels, customs, and many other businesses. (SQU, 2020).

The Oman government was affected by the COVID-19 mainly because it oils exporting countries, and Oman's economy depends almost entirely on oil. Nevertheless, the government is trying the best to reduce the COVID-19 impact on the business by implementing a package of measures to maintain Oman's financial stability. Besides, the government was also supporting small and medium enterprises by implementing special packages for them.

The LSE Middle East Center mentioned that the COVID-19 increased the Sultanate of Oman's pressure simultaneously with the COVID-19 pandemic, not to mention the situation prior to the pandemic. Since the government necessitating strict policy measures to mitigate the rapid spread of the Coronavirus between its citizens. (LSE Middle East Center, 2020).

\subsection{Response \& Measures}

Almost all countries globally implemented a wide range of control measures to minimize COVID-19 risk and consequences. The measurements have been treated in many different ways like:

- Travel bans.

- Quarantine measures.

- Self-isolation.

- Social distancing.

- Temporary suspension for many activities.

- Closure of the border. 
- Determine the staff percentage in companies and ministries; for example, in Oman, $30 \%$ only can work from an office, while $70 \%$ should work remotely.

- Sealing off or closing of endemic areas.

\subsection{Definition of Work from Home}

As per Messenger, J.C. and Gschwind, L., the Telework or Work from Home concept is old, and many scholars describe it as "a predecessor or an early form of work with New ICTs". In contrast, others describe it as a cloud-based work that any staff can work remotely without going to an office. Accordingly, the concept of Telework is old or not taken into scholars' consideration. Also, as per other researchers, Telework is "perceived as one of many co-existing modes of work like traditional office work, mobile work or virtual work." (Messenger \&amp; Gschwind, 2016).

\section{Work from Home Challenges}

One of the most challenging issues to move to Work from Home, is the resistance from some employer to adopting the WFH approach in their companies. The resistance can be traced back to the lack of confidence between the management and staff and vice versa. Also, there are many old school managers who prefer to supervise their staff directly, and they do not believe in technology. If managers are forced to shift to Work from Home approach, they will be looking for a solution enabling them to monitor staff.

Some research also shows some challenges related to using the latest collaboration systems while working from home, like lack of the communication richness available to traditional face-to-face teams. However, this is a sort of temporary resistance until all are used to deal with this new work style.

It is also noteworthy that the teamwork problem increasing in virtual meetings because of lack of experience and lack of trust in the technology. Many problems caused by Work from Home could be solved by "formalize team processes, clarify team goals, and build-in structural solutions to foster psychologically safe discussions."." (Kniffin, et al., 2020)

The same study also mentioned that staff might face some difficulties like their inability to request help from their coworkers and colleagues due to ashamed and embarrassment of requesting help.

In addition, there is a strong relationship between Work from Home and loneliness. In the case of many staff members, they need to talk with each other outside the work. But in the case of Work from Home most of the discussions and a lot of the argument will not exceed the work-related subjects. This may result in weakened linkages between staff themselves and with their management. The work's productivity and quality will affect as an inevitable result, and the consequence of staff relationship weakened.

Many staff members have to engage with digital products -especially Work from Home solutions- and services for the very first time. Some of them even have no internet access at home.

\section{Work from Home and productivity}

There are a lot of employees globally who prefer to Work from Home, as per a survey conducted by Buffer. The survey was showing that there is almost $99 \%$ of staff prefer to work remotely. At the same time, the same staff are to encourage their coworkers and colleagues to work remotely. They believe in the benefits of working remotely like flexible schedules, freedom to work from anywhere, and happy spending a lot of time with their families.

Productivity is Varies from one individual to another. While some staff can work more remotely, others cannot Work from Home. (Buffer, 2020)

A survey done by the Airtasker blog shows that Work from Home helps reduce transportation time. That time, they can spend to achieve more work or at least reduce staff stress, leading in various cases. According to the same survey, the staff working remotely spend more time doing physical exercises and eating homemade food, which improves their productivity.

The same study also mentioned that the ability to concentrate is higher in the office compared to Work from Home or remote work in general. The ability to concentrate is very important in terms of 
A Study on Work from Home: Opportunities and Challenges in the Electricity Sector in Omanduring COVID-19 -A Case Study.

productivity. So, to solve this issue, the employer should use a tool to manage the staff time and monitor their productivity.

\section{Opportunities}

The emergence of COVID-19 helped to digital transformation unprecedented and unpredictably. This change/effect is not limited to governments only, but it includes all sectors disproportionately based on each one's financial capabilities and technical and human resource capabilities. Many managers who did not believe in remote work in the past come back to the dominant culture and lack staff confidence. In contrast, staff believing in remote work and believing in its benefits.

A Gartner Survey reported that "82\% of Company Leaders Plan to Allow Employees to Work Remotely Some of the Time", (Gartner, 2020).Furthermore, a study titled "COVID-19 and the Workplace: Implications, Issues, and Insights for Future Research and Action", mentioned that almost more than half of companies covered in the survey had "more than $80 \%$ of their employees working from home during early stages of the COVID-19 pandemic - and estimated substantial long-term increases for remote work after the pandemic." (Kniffin, et al., 2020)

The opportunity to Work from Home increases employees' autonomy in scheduling and organizing their work (Bailey and Kurland 2002). Moreover, by offering agreeable working conditions, firms can attract and retain highly skilled and hard-working employees (DuBrin 1991). (Rupietta, et al., 2017)

The bright side of the COVID-19 it is opened opportunities for new and wide partnerships and collaborations between different organizations globally. Even at the manufacturing Industries \& delivery industry level, they are looking for a new solution to meet the needed demand resulting from COVID-19. (Payoneer blog, 2020)

\section{RESEARCH METHODOLOGY:}

\subsection{Introduction}

The right way to collect the data and analysis will inevitably lead to a right and accurate result and vice versa. It is vital to the reader understand how to collect the data, analyze it, and select it. The researcher's ability to explain the importance of the collected data and get the reader across the concept is critical.

The research's main objective was to investigate the expected technological challenges to Work from Home and its effect on the efficiency of the work in the electricity sector within the pandemic period. The research used a questionnaire that shared with almost 117 staff from the same sector to investigate Work from Home's challenges and opportunities. The importance of that questionnaire will help understand the staff challenges s well as the management of the electricity sector. some initiatives from the sector provide remote access for their staff, but it was limited to information technology staff. After the pandemic, there was an urgent need to provide remote access for a huge number of staff to facilitate access to the work network considering cybersecurity risks. The questionnaire helps to examine the impact of Work from Home on staff productivity and work performance. Based on that, the research can build public perceptions and give the right recommendation.

\subsection{Research Approach}

There are four approaches of research, Quantitative research, Qualitative research, mixed methods, and emancipatory. Qualitative research is a non-statistical method, but it depends on study issues in their natural settings to understand it deeply. Interview, text analysis, and case study research belongs to qualitative research.

In this research, Google form was the best tool that help the research designing an easy and accessible questionnaire. To make it ease for all participants to access it by smartphone or computer. Also, the researcher design the questionnaire and make clear questions and adding Arabic translation for participants who have a weak English understanding.

The questionnaire divided into many sections as the following: 
1- Explaining the questionnaire and its purpose.

2- Section 1: Personal details, to get some personal details about the staff.

3- Section 2: Computer literacy, to get information about staff's computer literacy. This will help to understand the level of knowledge of the participants.

4- Section 3: Home facilities, to understand staff capabilities to Work from Home.

5- Section 4: Security Awareness, to understand staff awareness about the cybersecurity issue and risks.

6- Section 5: Challenges \& opportunities, to understand the technical issue that may face the staff when working from home.

\subsection{Limitations of Research:}

Many challenges have militated against better and proper research. The challenges can summarize as the following:

1- Limitation of the primary resources related to the same study.

2- The researcher is working in information technology in the same sector. After the COVID-19 spread globally, the information technology departments one of the most intensively suffering from the workload for many reasons. Many sectors are not ready for digitization and supporting remote working. The top management pressure the IT departments to provide suitable solutions that help the business continue within the pandemic time.

3- There are some restrictions to do studies about the electricity sectors. For that reason, the questionnaire was to be distributed to some electricity subsidiaries.

4- Because of the challenges \#4, the number of participants was less than expectations.

5- Because of the time limitation, the researchers couldn't review other studies discussing the same topic.

\subsection{Research Analysis:}

After distributing the questionnaire and getting 117 responses, the researcher will analyze the collected data by using quantitative and qualitative methods. As mentioned earlier, the questionnaire was focusing on collecting data about the electricity staff's computer literacy. The collected data will help the researcher build a clear understanding of staff's ability to use the computing environment to remotely achieve their work. Based on that, the other challenges can be solved or at least give the researcher the ability to diagnose the technical problem.

The questionnaire in section \#3 focuses on staff's home facilities to understand the staff capabilities to Work from Home desiring the pandemic. Section \#4 focuses on the home worker's security awareness to understand staff awareness about the cybersecurity issue and risks. Also, to help in preparing a proper Work from Home Policy. Finally, the fifth section focuses on the Working Form Home approach's challenges and opportunities for both the companies and staff during the pandemic time.

\subsection{Data and Research Methodology:}

The descriptive-analytical and inferential statistics methods are the best method to analyze the collected data according to the research's primary objective in this study. The objective was to investigate the expected technological challenges to Work from Home and its effect on the efficiency of the work in the electricity sector within the pandemic period. Using descriptive statistics, the researcher shows the data as it, while the inferential statistics help the researcher extend beyond the immediate data alone. In this study, the researcher used inferential statistics to understand what the staff thinks about the Work from Home approach. Also, the same method can be used to judgments on specific phenomena. Nevertheless, descriptive statistics used to describe what is going $\mathrm{n}$ in the collected data. 
A Study on Work from Home: Opportunities and Challenges in the Electricity Sector in Omanduring COVID-19 -A Case Study.

\subsection{Descriptive Analysis:}

3.6.1. The Demographic Background of the Participants
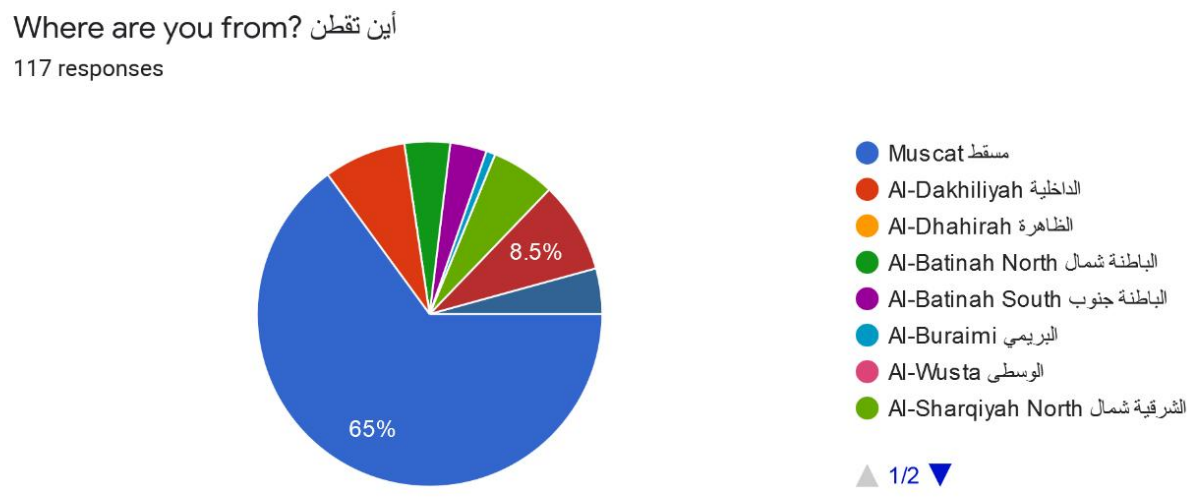

Figure13. The demographic background of the participants

Figure 13 shows that most participants were from Muscat, where the Al-Sharqiyah South comes second. The lowest number of participants was from Al-Buraimi. In this case, it is very hard to get accurate data about the internet speed in rural areas. Also, it is not possible to get a clearer picture of the computer literacy of participants.

3.6.2. Participants work location

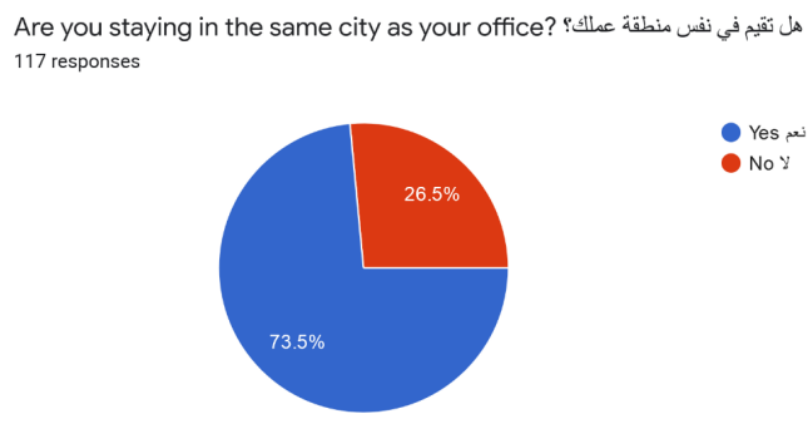

Figure14. Participants work location

The above figure shows that the staff who are working and staying at the same place are $73 \%$ percent of the total Participants.

3.6.3. Participants gender

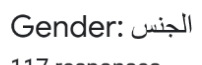

117 responses

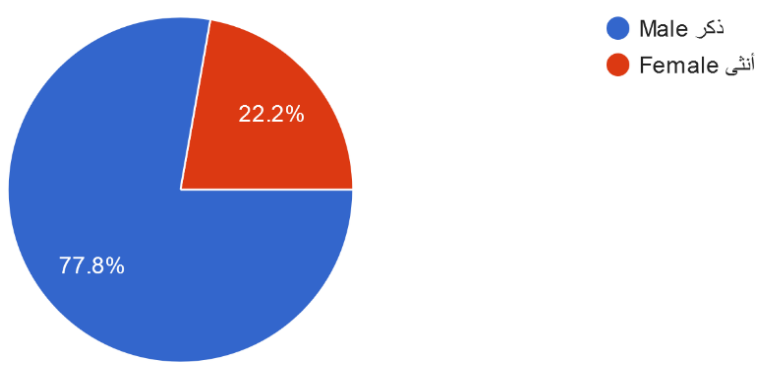

Figure15. Participants gender 
A Study on Work from Home: Opportunities and Challenges in the Electricity Sector in Omanduring COVID-19 -A Case Study.

Almost 63.8 percent of staff have a chance working from home previously, while 36.2 never worked from home. Maybe this is related to the nature of working in the electricity sector, as many staff working in the night shift have to visit electricity stations around Oman.

\subsubsection{Availability of the essential equipment at home}
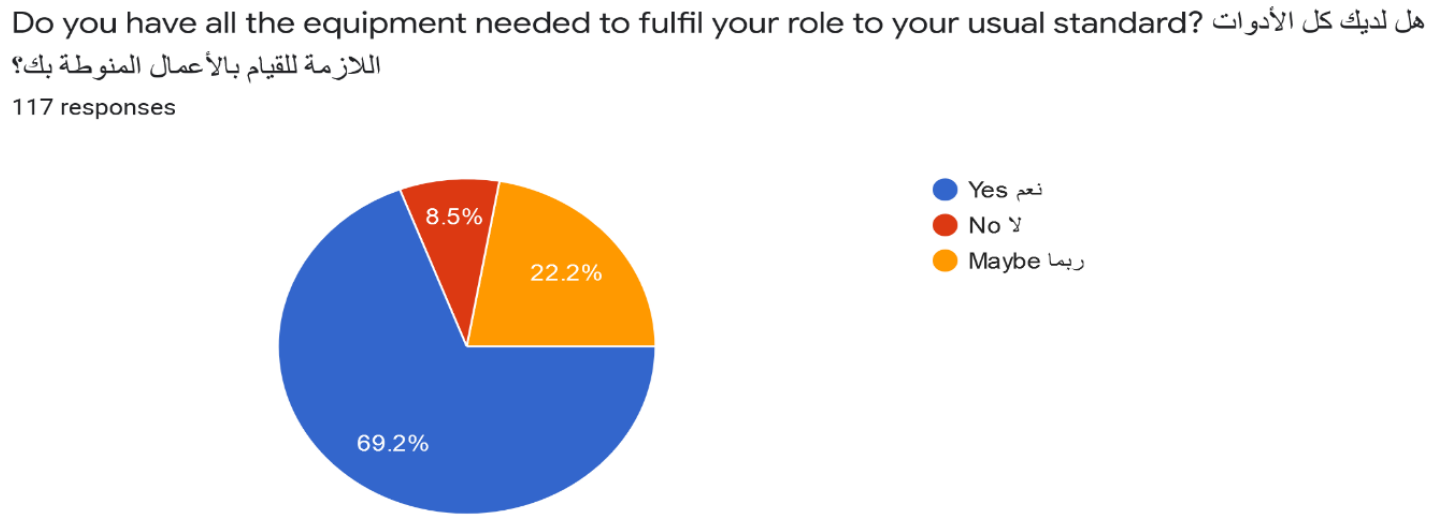

Figure21. Availability of the essential equipment at home

When staff working from home, they need equipment that helps them to achieve the required work. The above figure shows that 69.2 percent have the equipment, while 8.5 percent haven't the required equipment.

\subsubsection{Challenges \& opportunities}

The following figures $(26,27,28)$ show that there is plenty of staff who are interested in working remotely. This is a good indicator of the viability of adoptingtheworking from home approach in the electricity sector even after the pandemic time.

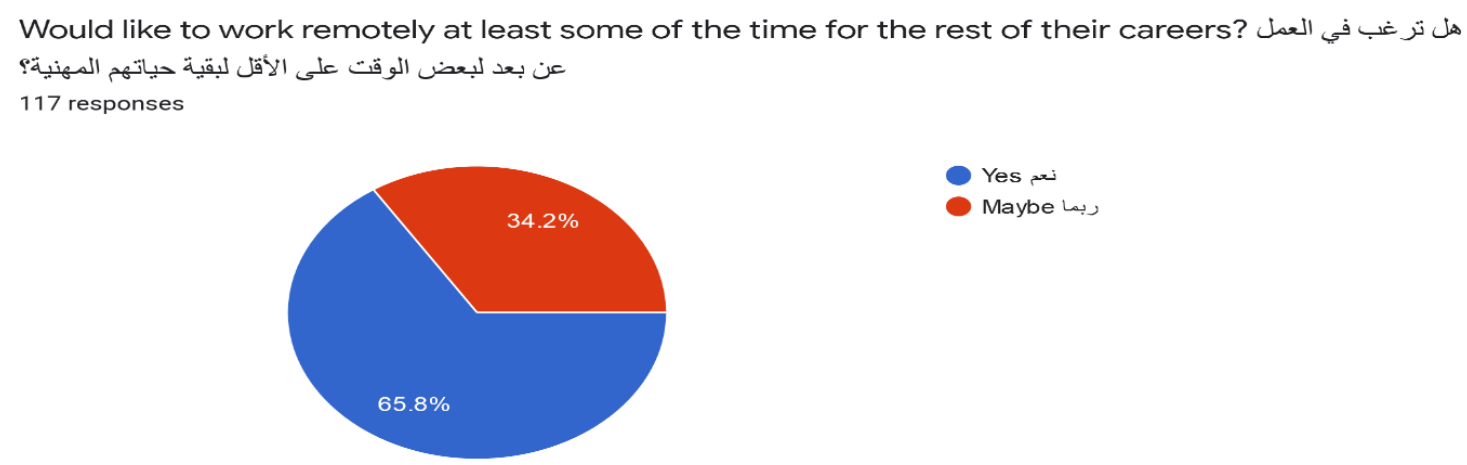

Figure26. Interest to Work from Home

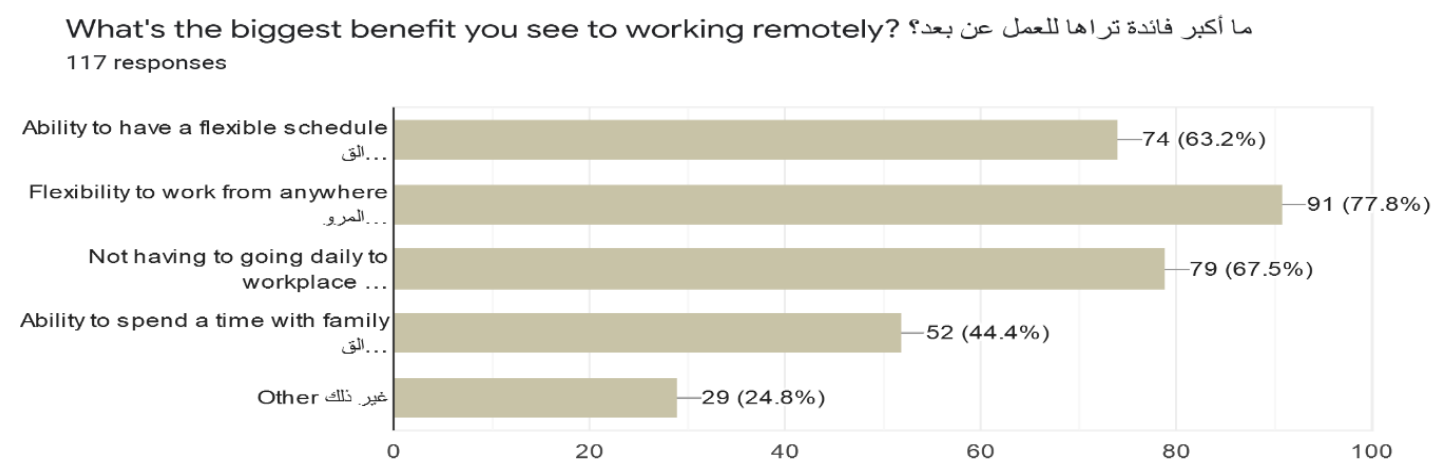

Figure27. Benefits of working from home 
Would you recommend remote work to others? هل تنصح الآخرين بالعمل عن بعد؟ 117 responses

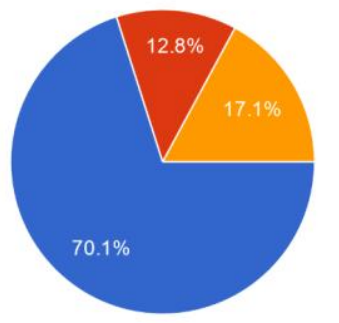

Figure28. Recommend others to Work from Home

\subsubsection{Adopting WFH in the Electricity Sector}

After the pandemic spread in Oman, the electricity sector start to force staff to Work from Home as per the government instructions. Many of the subsidiaries weren't ready to provide their staff the ability to access the work network remotely. Many companies haven't the sufficient resources to provide their services for staff because of the infrastructure challenges. After the COVID-19, the pandemic changes the game and drives digitalization in all sectors to unprecedented, unexpected, and unplanned levels.

Any companies that can't manage the disaster during the pandemic time will suffer from significant losses that could cause closes down.

Biggest_struggle_with_working_remotely

\begin{tabular}{|c|c|c|c|c|c|}
\hline & & Frequency & Percent & Valid Percent & Cumulative Percent \\
\hline \multirow[t]{19}{*}{ Valid } & Flexibility to work from anywhere & 1 & $.9 \%$ & $.9 \%$ & $.9 \%$ \\
\hline & Flexibility to work from anywhere " & 2 & $1.7 \%$ & $1.7 \%$ & $2.6 \%$ \\
\hline & Not having to going daily to workplace & 1 & $.9 \%$ & $.9 \%$ & $3.4 \%$ \\
\hline & Other " & 2 & $1.7 \%$ & $1.7 \%$ & $5.1 \%$ \\
\hline & "Ability to have a flexible schedule & 4 & $3.4 \%$ & $3.4 \%$ & $8.5 \%$ \\
\hline & "Collaboration and communication & 1 & $.9 \%$ & $.9 \%$ & $9.4 \%$ \\
\hline & "Not being able to unplug & 1 & $.9 \%$ & $.9 \%$ & $10.3 \%$ \\
\hline & Collaboration and communication & 3 & $2.6 \%$ & $2.6 \%$ & $12.8 \%$ \\
\hline & Distractions at home & 1 & $.9 \%$ & $.9 \%$ & $13.7 \%$ \\
\hline & FALSE & 5 & $4.3 \%$ & $4.3 \%$ & $17.9 \%$ \\
\hline & Finding a reliable Internet connection & 3 & $2.6 \%$ & $2.6 \%$ & $20.5 \%$ \\
\hline & Flexibility to work from anywhere & 3 & $2.6 \%$ & $2.6 \%$ & $23.1 \%$ \\
\hline & Loneliness & 1 & $.9 \%$ & $.9 \%$ & $23.9 \%$ \\
\hline & Maybe & 15 & $12.8 \%$ & $12.8 \%$ & $36.8 \%$ \\
\hline & No & 22 & $18.8 \%$ & $18.8 \%$ & $55.6 \%$ \\
\hline & Not being able to unplug & 2 & $1.7 \%$ & $1.7 \%$ & $57.3 \%$ \\
\hline & Not having to going daily to workplace & 1 & $.9 \%$ & $.9 \%$ & $58.1 \%$ \\
\hline & Other & 4 & $3.4 \%$ & $3.4 \%$ & $61.5 \%$ \\
\hline & Yes & 45 & $38.5 \%$ & $38.5 \%$ & $100.0 \%$ \\
\hline Total & & 117 & $100.0 \%$ & & \\
\hline
\end{tabular}

Table2. Challenges with working remotely

The above table (Table 2) showing that the biggest challenges of remote workers are:

- Collaboration and communication. (39.3\%)

- Loneliness (15.4\%)

- Not being able to unplug. (36.8\%)

- Distractions at home. (37.6\%)

- $\quad$ Staying motivated. (12\%)

- Taking vacation time. (12\%)

- Finding a reliable Internet connection. (35\%)

- Other. $(23.9 \%)$ 
A Study on Work from Home: Opportunities and Challenges in the Electricity Sector in Omanduring COVID-19 -A Case Study.

\subsubsection{Cybersecurity risks of WFH}

All IT department is concerned about the staff awareness, and they are considering the staff as the weakest link. One of the most significant risks for any IT department is the staff themselves. In case if the staff has sufficient knowledge on how to protect themselves from the internet security, and avoid to do any bad practice that may affect the company network.

\subsection{Summary of Analysis:}

In the "Study Results" chapter, the researcher provides the analysis of the data and findings. The research findings in this chapter were supported and powered by a literature review.

The main findings are as the followings:

1- 56.4 percent of the Participants have good computer literacy.

2- Staff who are working and staying at the same place are $73 \%$ percent of the total Participants.

3- The pre-graduate is the major of the staff who participate in the questionnaire.

4- $85 \%$ of staff have the initial experience, which will help them efficiently work remotely.

5- $91 \%$ of electricity staff prefers to use a phone call to communicate with other team members.

6- Electricity staff has good security awareness.

The above findings will help the researcher make a proper recommendation that may help to improve the current Work from Home in the electricity sector.

\section{CONClusion}

In this last chapter, the researcher will brief and discuss the findings of the study. This study aims to find the opportunities and challenges in Oman's electricity sector during the COVID-19 pandemic. In the end, the researcher provides some recommendations that would help enhance the sector's ability to meet the expectations during the pandemic period.

In March 2020, a lot of changes happened globally, Oman one of the countries affected by the COVID-19. Many economic activities were affected by the pandemic's consequence, and many other business activities suffered losses, and some companies closed in some cases. Some sectors were ready to adapt to the situation and the COVID-19 consequences and keep the provision of their services.

In Oman, the pandemic started to spread on Feb 24, 2020. On Apr 10, 2020, the Oman government procedure imposed precautionary measures to control the spreading pandemic. However, the government takes the measurement to control the pandemic, affecting a lot of business activities. One of the affected sectors is the Electricity sector. It is not possible to imagine countries in this century without Electricity. So the significant challenges begin in the electricity sector to keep working at full capacity even under government restrictions and measurements. The electricity sector has many responsibilities, and it should keep the service level and quality in top priority to ensure the pandemic not affecting the expectations and needs of beneficiaries.

There are a lot of technical issues facing the user s when they are starting Work from Home. Many users hasn't a good place to Work from Home and haven't the equipment that helps to achieve the required work. Without having a suitable place to work, the staff productivity will affect, as well as it may cause a psychological affliction.

Some staff work at the same place where they are staying, but they can go to the office during the lockdown time. In this case, they have to access remotely to achieve the required duties and responsibilities. The way to access it will be via the Internet. But as shown in the questionnaire finding, there is much staff suffering from internet slowness, especially outside the main cities.

The good thing is that the electricity sector is not affecting too much by the COVID-19 pandemic. The affection was limited, mainly because the sector has an excellent regulation to survive in a critical time. 


\subsection{Recommendations:}

\subsubsection{Cybersecurity}

As many staff working from Home, the sector must consolidate, monitor, and defend Internet gateways. Make sure to keep monitoring the traffic all the time. Simultaneously, the IT departments should work with the cybersecurity department -when applicable- to auditing the logs, processes, and activities related to internet gateways. The IT departments should be ready to shut down the access point if there are any suspicious activities.

The end-user is considered as the weakest link, so it should protect all devices which used by staff. All staff should have sufficient awareness about the security risks and assess the knowledge using professional tools to measure the awareness. The electricity sector should also negotiate with the telecommunication sector and work together to enhance the internet service level in Oman at all. Also, to upgrade the internet service to meet the end-user requirements as they are accessing remotely.

\subsubsection{Internet Speed}

Nowadays, the Internet is not a luxury, and it is one of the primary needs for anyone to achieve the work. Within the pandemic time, many staff is suffering from the Internet, which affecting their ability to contact their colleagues and managers. The Internet service provider should upgrade its services to meet the people's needs and expectations. A lot of staff cant achieve their work because they cant connect to the Internet because of the coverage. In some places, there are internet services, but they are suffering from slowness.

The electricity sector has the ability to support and work with ISP to improve and enhance the internet network in Oman in proportion to people's needs.

\subsubsection{Staff Rights}

During the pandemic HR department should work closely with the staff to solve their concerns and reduce it. If these concerns are not solved, it will affect the staff productivity.

\section{Future research:}

In conclusion, this study's result can be used to enrich future research related to the electricity sector and other sectors that looked forward to learning from the electricity sector experiences. The researcher also suggests focusing on improving internet connectivity and supporting working remotely in such disasters. Besides, it is recommended to study the staff's psychological well-being when working from home to ensure the health of staff not affect and make sure the organization's productivity staysat the top.

\section{REFERENCES /BIBLIOGRAPHY}

[1] Fitzpatrick, D. and Fishman, S., 2008. Work from Home Handbook. Berkeley, CA: Nolo.

[2] Heminsley, J., n.d.Work from Home.

[3] Spizman, R. and Johnson, T., 2014. Will Work from Home. New York: Berkley Books.

[4] The News. n.d., 7 Coronavirus Work from Home Tips - The Muse. Available from: <https:// www.themuse.com/advice/coronavirus-work-from-home-tips>. [May 01, 2020].

[5] Neerja Birla. n.d., How to Effectively Work from Home During a Pandemic. Available from: <https:// www.entrepreneur.com/article/350004>. [April 12, 2020].

[6] Courtney Connley, AbigailHess, Jennifer Liu. n.d., How the coronavirus pandemic will impact the future of Work. Available from: <https://www.cnbc.com/2020/04/29/how-the-coronavirus-pandemic-willimpact-the-future-of-work.html>. [April 15, 2020].

[7] Courtney Connley, AbigailHess, Jennifer Liu. n.d., How the coronavirus pandemic will impact the future of Work. Available from: <https://www.cnbc.com/2020/04/29/how-the-coronavirus-pandemic-willimpact-the-future-of-work.html>. [April 15, 2020].

[8] Arturo Chang. n.d., How business leaders can prevent work-from-home burnout during the COVID-19 pandemic - BNN Bloomberg. Available from: <https://www.bnnbloomberg.ca/how-business-leaders-canprevent-work-from-home-burnout-during-the-covid-19-pandemic-1.1430059>. [April 18, 2020].

[9] Scott Waldman, E\&E News. n.d., Telecommuting Could Outlive the Pandemic, Lowering Emissions Scientific American. Available from: <https://www.scientificamerican.com/article/telecommuting-couldoutlive-the-pandemic-lowering-emissions/>. [April 15, 2020]. 
A Study on Work from Home: Opportunities and Challenges in the Electricity Sector in Omanduring COVID-19 -A Case Study.

[10] Phone And Through. n.d., Work at Home Job Interview Questions, Answers, and Tips. Available from: <https://www.thebalancecareers.com/work-at-home-job-interview-questions-and-answers-2064262>. [June 10, 2020].

[11] Www.Etcio.Com. n.d., Is your organization ready for Work from Home (WFH)?, IT News, ET CIO. Available from: <https://cio.economictimes.indiatimes.com/news/corporate-news/is-your-organizationready-for-work-from-home-wfh/74644617>. [Jun 1, 2020].

[12] Sam Curry. n.d., 4 Major Cybersecurity Risks of Working From Home. Available from: <https://www.entrepreneur.com/article/348346>. [Jun 5, 2020].

[13] Hasan, Shahid\&Alaqeel, Turki\& Al-Badi, Abdullah \& Bhatt, Yagyavalk\& Al-Badi, Mohammed. (2019). Oman Electricity Sector: Features, Challenges and Opportunities for Market Integration Oman Electricity Sector: Features, Challenges and Opportunities for Market Integration. 10.30573/KS--2019-DP61.

[14] Charabi, Yassine\& Al-Badi, Abdullah \& Sorensen, Erik. (2014). Sultanate of Oman, Renewables Readiness Assessment. 10.13140/2.1.2109.2166.

[15] Hasan, Shahid\&Alaqeel, Turki\& Al-Badi, Abdullah \& Bhatt, Yagyavalk\& Al-Badi, Mohammed. (2019). Oman Electricity Sector: Features, Challenges and Opportunities for Market Integration Oman Electricity Sector: Features, Challenges and Opportunities for Market Integration. 10.30573/KS--2019-DP61.

[16] Steven Fraser And Dennis Mancl. n.d., COVID-19's Influence on the Future of Agile | SpringerLink. Available from: <https://link.springer.com/chapter/10.1007/978-3-030-58858-8_32>. [December 12, 2020].

[17] Bouziri H, Smith DRM, Descatha A, et al Working from Home in the time of COVID-19: how to best preserve occupational health? Occupational and Environmental Medicine 2020;77:509-510.

[18] IEA, Weekly electricity net generation in the European Union, 2015-2019 range compared with 2020, IEA, Paris https:/www.iea.org/data-and-statistics/charts/weekly-electricity-net-generation-in-theeuropean-union-2015-2019-range-compared-with-2020

[19] Messenger, J.C. and Gschwind, L. (2016) "Three Generations of Telework: New ICTs and the (R)Evolution from Home Office to Virtual Office". New Technology, Work and Employment31 (3), 195208

[20] Rupietta, Kira, Beckmann, and Michael (n.d.) Schmalenbach Business Review.vol. 2017. Springer Science+Business Media B.V.

[21] Kniffin, K.M., Narayanan, J., Anseel, F., Antonakis, J., Ashford, S.J., Bakker, A.B., Bamberger, P., Bapuji, H., Bhave, D.P., Choi, V.K. and Creary, S.J., 2020. COVID-19 and the Workplace: Implications, Issues, and Insights for Future Research and Action.

[22] Setyawan, F.E.B. and Lestari, R. (2020) "Challenges Of Stay-At-Home Policy Implementation During The Coronavirus (Covid-19) Pandemic In Indonesia”. JurnalAdministrasiKesehatan Indonesia8 (2), 15

[23] Bick, A., Blandin, A., and Mertens, K. (2020) "Work from Home After the COVID-19 Outbreak". Federal Reserve Bank of Dallas, Working Papers2020 (2017)

[24] Bajpai, N. (2011) Business Research Methods. Delhi: Pearson

[25] Noel, Lesley-Ann. (2016). Promoting an emancipatory research paradigm in Design Education and Practice. 10.21606/drs.2016.355.

[26] Making Research Easy. n.d., Research Design and Methodology | IntechOpen. Available from: <https://www.intechopen.com/books/cyberspace/research-design-and-methodology>. [December 20, 2020].

\section{WEBSITE:}

[1] Type. n.d., Oman Power Market | Growth, Trends, and Forecast (2019 - 2024). Available from: <https://www.mordorintelligence.com/industry-reports/oman-power-market>. [December 02, 2020].

[2] The Ministry Of. n.d., Global Transmission Report: Oman's Power Sector: Focus on grid expansion to support RE. Available from: <https://www.globaltransmission.info/archive.php?id=38960>. [December 02, 2020].

[3] ShynibenKoyakkil ...Issuu. Comoman. n.d., PDF.js viewer. Available from: <https://omanpwp.om/ Docs/Oman\%20Electricity\%20Market\%20Guide_2017-12-241.pdf>. [December 02, 2020].

[4] Royal Decrees. n.d., Royal Decree 78/2004 - Sector Law English.pdf. Available from: <https://omanpwp. om/PDF/Sector\%20Law\%20English.pdf>. [December 02, 2020].

[5] Country. n.d., Archived: WHO Timeline - COVID-19. Available from: <https://www.who.int/news /item/27-04-2020-who-timeline---covid-19>. [December 02, 2020]. 
[6] Impact of COVID 19 on development in Oman. Available from: <about:reader?url=https\%3A\%2F $\% 2$ Fwww.squ.edu.om\%2Fresearch\%2FResearch-Output $\% 2$ FLatest-Research-Highlights $\% 2$ FArticleID $\%$ 2F865\%2FImpact-of-COVID-19-on-development-in-Oman>. [December 12, 2020].

[7] Francis Owtram And. n.d., Oman in the COVID-19 Pandemic: People, Policy and Economic Impact | Middle East Centre. Available from: <https://blogs.lse.ac.uk/mec/2020/07/23/oman-in-the-covid-19pandemic-people-policy-and-economic-impact/>. [December 12, 2020].

[8] Country. n.d., The Global Economic Outlook During the COVID-19 Pandemic: A Changed World. Available from: <https://www.worldbank.org/en/news/feature/2020/06/08/the-global-economic-outlookduring-the-covid-19-pandemic-a-changed-world>. [December 16, 2020].

[9] The Numbersprediction Consensus. n.d., The Economic Impact of COVID-19: According to Business Leaders. Available from: <https://www.visualcapitalist.com/economic-impact-covid-19/>. [December 16, 2020].

[10] Doing Something That. n.d., The stock market and the economy: Insights from the COVID-19 crisis | VOX, CEPR Policy Portal. Available from: <https://voxeu.org/article/stock-market-and-economyinsights-covid-19-crisis>. [December 16, 2020].

[11] The Team At. n.d., Infographic: The History of Telecommuting - LiquidPlanner. Available from: <https:// www.liquidplanner.com/blog/infographic-the-history-of-telecommuting/>. [December 16, 2020].

[12] The Water Cooler. n.d., We Work Remotely | Learn more about the History of Remote Work and where it's going!. Available from: <https://weworkremotely.com/history-of-remote-work>. [December 17, 2020].

[13] The Tv. n.d., Working from Home 101: The Complete Guide to Remote Work [+Infographic] - Sage HR Blog. Available from: <https://blog.sage.hr/working-home-complete-guide-remote-work/>. [December 17, 2020].

[14] Bob Violino. n.d., IT's 10 biggest challenges amid COVID-19 | CIO. Available from: <https:// www.cio.com/article/3543068/its-10-biggest-challenges-amid-covid-19.html>. [December 17, 2020].

[15] Cyber Criminals Are. n.d., COVID-19: tackling cyber security challenges - Financier Worldwide. Available from: <https://www.financierworldwide.com/covid-19-tackling-cyber-security-challenges>. [December 17, 2020].

[16] Clicking The Button. n.d., Top Emerging Business Opportunities Post-COVID-19. Available from: $<$ https://blog.payoneer.com/e-sellers/trending/business-opportunities-covid19/>. [December 17, 2020].

[17] Solving Social Problems. Some. n.d., All You Need to Know About Research Methodology - Thesis Hub. Available from: <https://thesishub.org/all-you-need-to-know-about-research-methodology/\#researchmethods-and-research-methodology>. [December 19, 2020].

[18] Writing your Dissertation: Methodology | SkillsYouNeed. Available from: <https://www.skillsyouneed.com/learn/dissertation-methodology.html>. [December 19, 2020].

[19] Business Editorial Team. n.d., Can Employees Be More Productive From Home? - business.com. Available from: <https://www.business.com/articles/are-employees-more-productive-working-fromhome/>. [December 19, 2020].

[20] Buffer In Partnership. n.d., State of Remote Work 2019 | Buffer. Available from: <https://buffer.com/stateof-remote-work-2019>. [December 19, 2020].

[21] Airtasker. n.d., The Benefits of Working From Home - Airtasker Blog. Available from: <https:// www.airtasker.com/blog/the-benefits-of-working-from-home/>. [December 19, 2020].

[22] 10 benefits of remote working. Available from: <https://www.telegraph.co.uk/technology/connectingbritain/remote-working-benefits/>. [December 19, 2020].

[23] Ooredoo 4G Network Coverage Expanded by more than 750 Locations. Available from: <https:// www.ooredoo.om/AboutOoredoo/Media/PressReleases/DetailPressRelease/tabid/2375/ArticleId/3341/Oor edoo-4G-Network-Coverage-Expanded-by-more-than-750-Locations.aspx>. [December 19, 2020].

[24] 5G. Available from: <https://www.omantel.om/Personal/AtHome/5G-Home>. [December 19, 2020].

[25] Coverage Map. Available from: <https://www.omanbroadband.om/Coverage-Map.html>. [December 19, 2020].

[26] Awasr Site. Available from: <https://www.awasr.om/login>. [December 19, 2020].

[27] Types of Philosophies in Research/Dissertation/Thesis Work?. Available from: <https://www.mbahelp24. com/research-philosophy-dissertationthesis/>. [December 19, 2020].

[28] Sampling Methods | Types and Techniques Explained. Available from: <https://www.scribbr.com/ methodology/sampling-methods/>. [December 20, 2020]. 
A Study on Work from Home: Opportunities and Challenges in the Electricity Sector in Omanduring COVID-19 -A Case Study.

[29] William M.K. Trochim. n.d., Descriptive Statistics | Research Methods Knowledge Base. Available from: <https://conjointly.com/kb/descriptive-statistics/>. [December 20, 2020].

[30] Office And Gradual. n.d., Keeping our employees and partners safe during \#coronavirus. Available from: <https://blog.twitter.com/en_us/topics/company/2020/keeping-our-employees-and-partners-safe-duringcoronavirus.html >. [December 20, 2020].

[31] Alex Castro. (2020) Google pushes return to office to September and will test flexible work week - The Verge. Retrieved Dec 20, 2021, from https://www.theverge.com/2020/12/14/22175150/google-returnoffice-september-flexible-work-week-coronavirus-pandemic-sundar-pichai.

Citation: Saif Said Hamed Al Badi, Dr. Syed Aulia Mohiuddin. "A Study on Work from Home: Opportunities and Challenges in the Electricity Sector in Omanduring COVID-19 -A Case Study." International Journal of Managerial Studies and Research (IJMSR), vol 9, no. 6, 2021, pp. 11-26. doi: https://doi.org/10.20431/23490349.0906002.

Copyright: () 2021 Authors. This is an open-access article distributed under the terms of the Creative Commons Attribution License, which permits unrestricted use, distribution, and reproduction in any medium, provided the original author and source are credited. 